\title{
Anion- $\pi$ interactions in layered structures of salts of 5-(hydroxyimino) quinolin-8-one and related salts
}

\author{
PRITHIVIRAJ KHAKHLARY and JUBARAJ B BARUAH* \\ Department of Chemistry, Indian Institute of Technology Guwahati, North Guwahati 781 039, Assam, India \\ e-mail: juba@iitg.ernet.in
}

MS received 3 July 2014; revised 23 October 2014; accepted 24 October 2014

\begin{abstract}
Relevance of anion- $\pi$ interactions in chloride, bromide, nitrate and perchlorate salts of 5(hydroxyimino)quinolin-8-one are discussed. Structures of nitrate salt of 5-aminoquinoline as well as nitrate salt of 4-hydroxyquinazoline are compared with the structure of nitrate salt of 5-(hydroxyimino)quinolin8 -one. From such a comparison, two different arrangements of nitrate ions with respect to the respective cations are discerned. Nitrate ions are sandwiched between aromatic planes of cations in nitrate salts of 5(hydroxyimino)quinolin-8-one or 4-hydroxyquinazoline; whereas, nitrate ions are in oblique positions with respect to aromatic planes of counter cations in nitrate salt of 5-aminoquinoline. Binding constants of different nitrate salts in solution are determined by UV-visible spectroscopic titrations. Solution study shows formation of ion-pairs of these salts in solution.
\end{abstract}

Keywords. Layered structures; anion- $\pi$ interactions; quinoline salts; crystal structures; optical properties

\section{Introduction}

Anion- $\pi$ interactions present in different organic compounds are well studied. ${ }^{1-15}$ For such interactions ${ }^{1-12}$ to be present in a packing pattern or in an isolated compound, geometrically favourable orientations of anions at appropriate distances with respect to $\pi$-clouds ${ }^{13-15}$ are essential. In general, different types of anions such as symmetric spherical halide ions, symmetric and nonplanar polyatomic ions like $\mathrm{ClO}_{4}^{-}, \mathrm{SO}_{4}^{2-}, \mathrm{SiX}_{6}^{2-}, \mathrm{BX}_{4}^{-}$, $\mathrm{PX}_{6}^{-}(\mathrm{X}=$ halogen $)$, symmetric planar $\mathrm{NO}_{3}^{-}, \mathrm{N}_{3}^{-}$ions, and unsymmetric planar $\mathrm{SCN}^{-}$ion, unsymmetric and non-planar anions like $\mathrm{HPO}_{4}^{2-}, \mathrm{H}_{2} \mathrm{PO}_{4}^{-}, \mathrm{HSO}_{4}^{-}$interact with $\pi$-clouds of molecules. ${ }^{5,8-11}$ Anion- $\pi$ interactions commonly occur with suitable molecule through nesting, perching or encapsulation of anions. ${ }^{16-23}$ Some of the ways to hold anions at appropriate positions with respect to $\pi$-clouds through anion- $\pi$ interactions are shown in figure 1(i)-(iii). Intermolecular $\mathrm{Y}-\mathrm{H}^{\cdots}{ }^{\prime} \mathrm{X}$ interactions to hold anions on top of a planar aromatic rings (figure $1(\mathbf{i})$ ) are extensively studied. ${ }^{24,25}$ Anion- $\pi$ interactions may also occur in tight packed structures such as the one shown in figure 1 (ii and iii). Among these two types of arrangements, packing as shown in (ii) of figure 1 will minimize repulsions between similar ions. Such arrangements of $\pi$-aromatic rings containing organo-cations have not been explored. Another way of

\footnotetext{
*For correspondence
}

arranging cations and anions to confer anion- $\pi$ interactions is through encapsulation of anions by cations as shown in representation (iii) of figure 1. This arrangement is observed in systems such as nitrate ions held within aromatic hosts possessing cage-like structures. ${ }^{15}$ Nitrate ions generally show $\mathrm{O}^{\cdots} \pi$ interactions ${ }^{26,27}$ or get sandwiched between aromatic rings. ${ }^{26-28}$ In this study, structure and spectroscopic properties of salts 1-4 of 5-(hydroxyimino)quinolin-8-one (hqn) (figure 2) and 5-aminoquinolinium nitrate (Hamq. $\mathrm{NO}_{3}, \mathbf{5}$ ), 4hydroxyquinazolinium nitrate (Hquin. $\mathbf{N O}_{3}, \mathbf{6}$ ) are taken up to reveal the importance of anion- $\pi$ interactions in them.

\section{Experimental}

\subsection{Synthesis and characterization}

5-(hydroxyimino)quinolin-8-one was prepared by reported procedure..$^{29,30}$ Salts 1-4 were prepared by adding hydrochloric, hydrobromic, nitric or perchloric acid ( $1 \mathrm{~mL}$ in each case) to solution of 5-(hydroxyimino)quinolin-8-one $(0.173 \mathrm{~g}, 1 \mathrm{mmol})$ in dimethylformamide $(15 \mathrm{~mL})$. A homogeneous solution in each case was formed. Each salt crystallized at room temperature after about a week. Salt Hamq. $\mathbf{N O}_{\mathbf{3}}(\mathbf{5})$ and Hquin. $\mathrm{NO}_{3}(6)$ were prepared in a similar procedure to that of salt 1-4. In case of Hamq. $\mathbf{N O}_{3}, 5$ aminoquinoline $(0.144 \mathrm{~g}, 1 \mathrm{mmol})$ and for Hquin. $\mathbf{N O}_{3}$, 


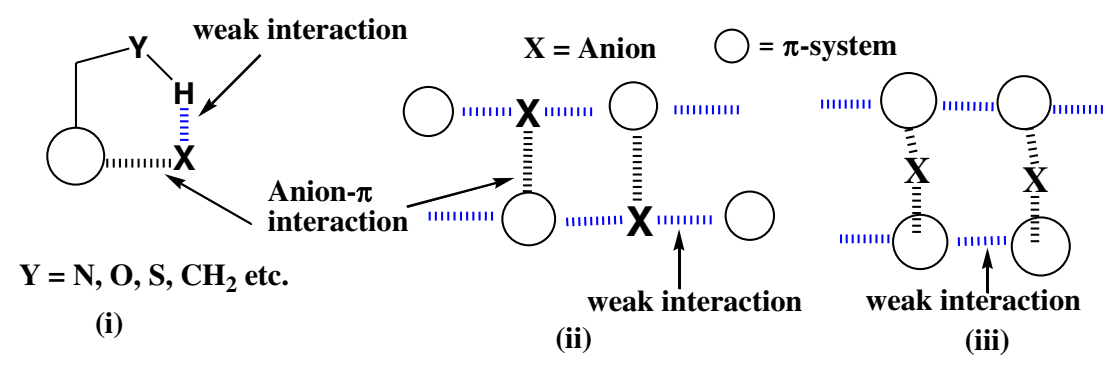

Figure 1. Some ways for anion- $\pi$ interactions (i) through support of a host; (ii) anion and cation placed at alternate positions; (iii) anions sandwiched by cations.

4-hydroxyquinazoline $(0.146 \mathrm{~g}, 1 \mathrm{mmol})$ was used with conc. nitric acid $(1 \mathrm{~mL})$ respectively.

2.1a Salt 1 (Hhqn.Cl): Yield $\sim 93 \%$. IR (KBr, $\mathrm{cm}^{-1}$ ): 3447 (s), 2919 (w), 2816 (w), 2746 (w), 1676 (m), 1659 (m), $1618(\mathrm{~m}), 1582(\mathrm{w}), 1526(\mathrm{w}), 1326(\mathrm{w})$, 1304 (w), 1276 (w), 1102 (w), $1080(w), 991(w), 822$ (w), 803 (w), 667 (w). ${ }^{1} \mathrm{H}-\mathrm{NMR}$ (DMSO-d ${ }^{6}, 400 \mathrm{MHz}$, ppm ), 13.79 (s, 1H), 8.90 (q, $J=1.2 \mathrm{~Hz}, 1 \mathrm{H}), 8.65$ $(\mathrm{d}, J=8.4 \mathrm{~Hz}, 1 \mathrm{H}), 8.06(\mathrm{q}, J=4.4 \mathrm{~Hz}, 1 \mathrm{H}), 7.82$ $(\mathrm{d}, J=10.4 \mathrm{~Hz}, 1 \mathrm{H}), 6.79(\mathrm{~d}, J=10.4 \mathrm{~Hz}, 1 \mathrm{H}), 3.15$ $(\mathrm{s}, 1 \mathrm{H})$. ESI Mass found $175.1582(\mathrm{~m}+\mathrm{H}) / \mathrm{z}$; calculated for cation $\mathrm{C}_{9} \mathrm{H}_{7} \mathrm{~N}_{2} \mathrm{O}_{2}\left(\mathrm{~m}^{+} / \mathrm{z}\right) 175.1614$.

2.1b Salt 2 (Hhqn.Br): Yield $\sim 90 \%$. IR (KBr, $\mathrm{cm}^{-1}$ ): 3437 (s), 2920 (w), 2825 (w), 1676 (m), 1638 (m), $1617(\mathrm{~m}), 1582(\mathrm{w}), 1526(\mathrm{w}), 1324(\mathrm{w}), 1304$ (w), $1276(\mathrm{w}), 1101(\mathrm{w}), 991(\mathrm{w}), 820(\mathrm{w}), 804(\mathrm{w})$, 786 (w), 665 (w). ${ }^{1} \mathrm{H}-\mathrm{NMR}$ (DMSO-d ${ }^{6}, 400 \mathrm{MHz}, \mathrm{ppm}$ ): $13.75(\mathrm{~s}, 1 \mathrm{H}), 8.94(\mathrm{q}, J=1.6 \mathrm{~Hz}, 1 \mathrm{H}), 8.79(\mathrm{~d}, J=$ $8.4 \mathrm{~Hz}, 1 \mathrm{H}), 8.09(\mathrm{q}, J=4.8 \mathrm{~Hz}, 1 \mathrm{H}), 7.92(\mathrm{~d}, J=10.4$ $\mathrm{Hz}, 1 \mathrm{H}), 6.84(\mathrm{~d}, J=10.4 \mathrm{~Hz}, 1 \mathrm{H}), 3.12(\mathrm{~s}, 1 \mathrm{H})$. ESI Mass found $175.1582\left(\mathrm{~m}^{+} / \mathrm{z}\right)$; calculated for $\mathrm{C}_{9} \mathrm{H}_{7} \mathrm{~N}_{2} \mathrm{O}_{2}$ cation $\left(\mathrm{m}^{+} / \mathrm{z}\right) 175.1614$.

2.1c Salt 3 (Hhqn. $\mathrm{NO}_{3}$ ): Yield $\sim 86 \%$. IR (KBr, $\mathrm{cm}^{-1}$ ): 3445 (m), 3050 (m), 2923 (w), 2832 (m), 2772 (w), 1677(m), $1661(\mathrm{~m}), 1617(\mathrm{~m}), 1582(\mathrm{w}), 1526$ (w), 1384 (s), 1356 (w), 1325 (w), 1304 (w), 1277 (w), $1101(\mathrm{w}), 1084(\mathrm{w}), 992(\mathrm{~m}), 820(\mathrm{w}), 805(\mathrm{w}), 785(\mathrm{w})$,
665 (w). ${ }^{1} \mathrm{H}-\mathrm{NMR}$ (DMSO-d $\left.{ }^{6}, 400 \mathrm{MHz}\right): 13.75$ (s, 1H), $9.18(\mathrm{q}, J=1.6 \mathrm{~Hz}, 1 \mathrm{H}), 9.03(\mathrm{~d}, J=8.4 \mathrm{~Hz}, 1 \mathrm{H}), 8.51$ $(\mathrm{q}, J=4.4 \mathrm{~Hz}, 1 \mathrm{H}), 7.90(\mathrm{~d}, J=10.4,1 \mathrm{H}), 7.21$ $(\mathrm{d}, J=10.4,1 \mathrm{H}), 3.12(\mathrm{~s}, 1 \mathrm{H}),{ }^{13} \mathrm{C}$ (DMSO-d ${ }^{6}, 100$ $\mathrm{MHz}, \mathrm{ppm})$ 181.4, 149.2, 144.3, 141.9, 134.1, 131.1, 130.7, 127.9, 126.1. ESI Mass found $175.1631\left(\mathrm{~m}^{+} / \mathrm{z}\right)$; calculated for $\mathrm{C}_{9} \mathrm{H}_{7} \mathrm{~N}_{2} \mathrm{O}_{2}$ cation $\left(\mathrm{m}^{+} / \mathrm{z}\right)$ 175.1614.

2.1d Salt 4 (Hhqn.ClO 4 ): Yield $\sim 84 \%$. IR (KBr, $\mathrm{cm}^{-1}$ ): 3447 (w), 3050 (m), 2921 (m), 2831(m), 2773 (w), $1678(\mathrm{~m}), 1617(\mathrm{~m}), 1582(\mathrm{w}), 1526(\mathrm{w}), 1423$ (w), $1393(\mathrm{w}), 1355(\mathrm{w}), 1325(\mathrm{w}), 1304(\mathrm{w}), 1277(\mathrm{~m})$, 1142 (s), 1115 (s), 1102 (s), 1089 (s), 1046 (w), 991 (s), $820(\mathrm{w}), 805(\mathrm{w}), 785(\mathrm{w}), 665(\mathrm{w}), 648(\mathrm{w}), 636(\mathrm{w})$, 626 (w). ${ }^{1} \mathrm{H}-\mathrm{NMR}$ (DMSO-d ${ }^{6}, 400 \mathrm{MHz}, \mathrm{ppm}$ ): 13.75 $(\mathrm{s}, 1 \mathrm{H}), 8.87(\mathrm{q}, J=1.6 \mathrm{~Hz}, 1 \mathrm{H}), 8.62(\mathrm{~d}, J=8.4$ $\mathrm{Hz}, 1 \mathrm{H}), 8.02(\mathrm{q}, J=4.8 \mathrm{~Hz}, 1 \mathrm{H}), 7.78(\mathrm{~d}, J=10.4$ $\mathrm{Hz}, 1 \mathrm{H}), 6.76$ (d, $J=10.4 \mathrm{~Hz}, 1 \mathrm{H}), 3.12$ (s, 1H). ESI Mass found $175.1531\left(\mathrm{~m}^{+} / \mathrm{z}\right)$; calculated for $\mathrm{C}_{9} \mathrm{H}_{7} \mathrm{~N}_{2} \mathrm{O}_{2}$ cation $\left(\mathrm{m}^{+} / \mathrm{z}\right) 175.1614$.

Caution: Perchlorate salts are thermally hazardous; so they should be carefully dealt while heating.

2.1e Salt 5 (Hamq. NO$_{3}$ ): Yield: $\sim 90 \%$. IR ( $\mathrm{KBr}$, $\mathrm{cm}^{-1}$ ): 3399 (bs), 3086 (bs), 2924 (bs), 1764 (w), 1638 (m), 1590 (s), 1383 (bs), 1223 (m), 1033 (w), 826 (s). ${ }^{1} \mathrm{H}-\mathrm{NMR}$ (DMSO-d $\left.{ }^{6}, 400 \mathrm{MHz}, \mathrm{ppm}\right): 13.10(\mathrm{~s}, 1 \mathrm{H})$, $8.76(\mathrm{~m}, 1 \mathrm{H}), 7.87(\mathrm{~m}, 1 \mathrm{H}) 7.25(\mathrm{~m}, 3 \mathrm{H}), 7.05(\mathrm{~m}$, $1 \mathrm{H}), 4.62(\mathrm{bs}, 2 \mathrm{H})$. ESI Mass found $145.1718\left(\mathrm{~m}^{+} / \mathrm{z}\right)$; calculated for $\mathrm{C}_{9} \mathrm{H}_{7} \mathrm{~N}_{2}$ cation $\left(\mathrm{m}^{+} / \mathrm{z}\right)$ 145.0766.

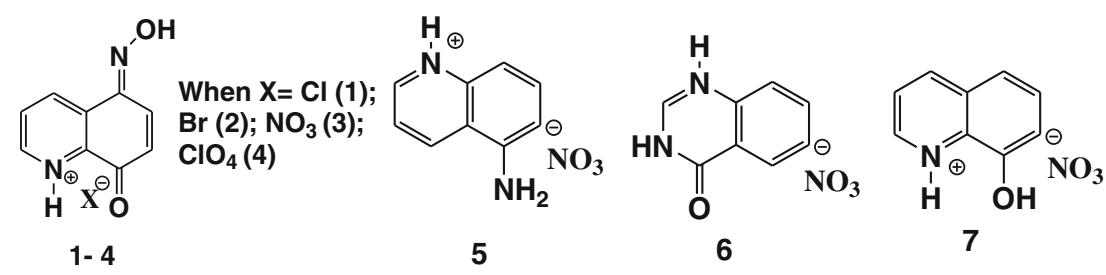

Figure 2. Various salts of 5-(hydroxyimino)quinolin-8-one and quinoline derivatives. 
2.1f Salt 6 (Hquin. $\mathrm{NO}_{3}$ ): Yield: $\sim 96 \%$. IR (KBr, $\mathrm{cm}^{-1}$ ): 3431 (bs), 3016 (s), 2804 (bs), 1721 (s), 1652 (m), 1576 (w), 1384 (s), 1291 (w), 1227 (w), 824 9w), 773 (m). ${ }^{1} \mathrm{H}-\mathrm{NMR}$ (DMSO-d ${ }^{6}, 400 \mathrm{MHz} . \mathrm{ppm}$ ): 12.2 (s, $2 \mathrm{H}), 8.16(\mathrm{t}, J=8.4 \mathrm{~Hz}, 2 \mathrm{H}), 7.81(\mathrm{t}, J=8 \mathrm{~Hz}, 1 \mathrm{H})$, $7.67(\mathrm{~d}, J=8.2 \mathrm{~Hz}, 1 \mathrm{H}), 7.50(\mathrm{t}, J=8 \mathrm{~Hz})$. ESI Mass found $147.1655\left(\mathrm{~m}^{+} / \mathrm{z}\right)$; calculated for $\mathrm{C}_{8} \mathrm{H}_{7} \mathrm{~N}_{2} \mathrm{O}$ cation $\left(\mathrm{m}^{+} / \mathrm{z}\right) 147.0558$.

\subsection{Structure determination}

X-ray single crystal diffraction data were collected with $\operatorname{Mo} K_{\alpha}$ radiation $(\lambda=0.71073 \AA)$ using a Bruker Nonius SMART CCD diffractometer equipped with a graphite monochromatic. SMART software was used for data collection and also for indexing reflections and determining unit cell parameters. Data were integrated using SAINT software. ${ }^{31}$ Structures were solved by direct methods and refined by full-matrix least-squares calculations using SHELXTL software. ${ }^{31}$ All atoms other than hydrogen atoms were refined in anisotropic approximation against $F^{2}$ of all reflections. In case of salt 4, one oxygen atom of perchlorate ion is disordered and disorder is resolved by sharing its position in two equivalent positions. Crystallographic parameters are listed in table 1.

\subsection{Binding constants}

Benesi-Hildebrand equation ${ }^{32}$ was used to evaluate binding constant of respective salt.

$$
1 /\left(A-A_{0}\right)=1 /\left\{K\left(A_{\max }-A_{0}\right) C\right\}+1 /\left(A_{\max }-A_{0}\right)
$$

$\mathrm{A}_{0}$ is absorbance of aromatic heterocyclic compound at absorbance maximum, $\mathrm{A}$ is observed absorbance at a concentration $\mathrm{C}$ of the anion, $\mathrm{A}_{\max }$ is maximum absorbance value, $\mathrm{K}$ is binding constant $\left(\mathrm{M}^{-1}\right)$.

\subsection{DFT calculation}

Ground state geometries of chloride (1) and nitrate salt (3) were optimized using GaussView 4.1 with B3LYP functional.

Table 1. Crystallographic parameters of 1-6

\begin{tabular}{|c|c|c|c|c|c|c|}
\hline Salt No. & 1 & 2 & 3 & 4 & 5 & 6 \\
\hline Formula & $\mathrm{C}_{9} \mathrm{H}_{7} \mathrm{~N}_{2} \mathrm{O}_{2} \mathrm{Cl}$ & $\mathrm{C}_{9} \mathrm{H}_{7} \mathrm{~N}_{2} \mathrm{O}_{2} \mathrm{Br}$ & $\mathrm{C}_{9} \mathrm{H}_{7} \mathrm{~N}_{3} \mathrm{O}_{5}$ & $\mathrm{C}_{18} \mathrm{H}_{14} \mathrm{~N}_{4} \mathrm{OCl}_{2}$ & $\mathrm{C}_{9} \mathrm{H}_{9} \mathrm{~N}_{3} \mathrm{O}_{3}$ & $\mathrm{C}_{8} \mathrm{H}_{7} \mathrm{~N}_{3} \mathrm{O}_{4}$ \\
\hline Mol. wt. & 210.62 & 255.08 & 237.18 & 565.23 & 207.19 & 209.17 \\
\hline CCDC No & 914800 & 914799 & 914801 & 914803 & 944122 & 944121 \\
\hline Crystal system & Monoclinic & Monoclinic & Monoclinic & Monoclinic & Monoclinic & Monoclinic \\
\hline Space group & $P 2_{1} / \mathrm{m}$ & $P 2_{1} / \mathrm{m}$ & $P 2_{1} / \mathrm{c}$ & $C 2 / \mathrm{c}$ & $P 2_{1} / \mathrm{c}$ & $P 2_{1} / \mathrm{c}$ \\
\hline Temperature (K) & $296(2)$ & $296(2)$ & $296(2)$ & $296(2)$ & $296(2)$ & $296(2)$ \\
\hline Wavelength (§) & 0.71073 & 0.71073 & 0.71073 & 0.71073 & 0.71073 & 0.71073 \\
\hline $\mathrm{a}(\AA)$ & $7.7196(4)$ & $7.7467(8)$ & $10.1679(3)$ & $14.2720(9)$ & $9.0298(8)$ & $5.2491(4)$ \\
\hline b $(\AA)$ & $6.5230(3)$ & $6.7200(9)$ & $6.8254(2)$ & $7.3529(3)$ & $4.9832(7)$ & $10.7683(7)$ \\
\hline$c(\AA)$ & $9.1079(5)$ & $9.2752(10)$ & $14.2890(5)$ & $21.2213(12)$ & 20.8468(19) & $16.3714(18)$ \\
\hline$\alpha\left(^{\circ}\right)$ & 90.00 & 90.00 & 90.00 & 90.00 & 90.00 & 90.00 \\
\hline$\beta\left(^{\circ}\right)$ & $96.577(3)$ & $94.889(8)$ & $95.034(2)$ & $96.845(4)$ & $93.080(9)$ & $95.572(9)$ \\
\hline$\gamma\left({ }^{\circ}\right)$ & 90.00 & 90.00 & 90.00 & 90.00 & 90.00 & 90.00 \\
\hline $\mathrm{V}\left(\AA^{3}\right)$ & $455.61(4)$ & 481.09(10) & $987.83(5)$ & 2211.1(2) & $936.70(17)$ & $921.01(14)$ \\
\hline $\mathrm{Z}$ & 2 & 2 & 4 & 4 & 4 & 4 \\
\hline Density $/ \mathrm{gcm}^{-3}$ & 1.535 & 1.761 & 1.595 & 1.698 & 1.469 & 1.508 \\
\hline Abs. Coeff. $/ \mathrm{mm}^{-1}$ & 0.391 & 4.245 & 0.133 & 0.375 & 0.113 & 0.124 \\
\hline Abs. correction & None & multi-scan & None & multi-scan & None & None \\
\hline $\mathrm{F}(000)$ & 216 & 252 & 488 & 1152 & 432 & 432 \\
\hline Total No. of reflections & 890 & 894 & 1785 & 1996 & 1673 & 1664 \\
\hline Reflections, I > $2 \sigma(\mathrm{I})$ & 784 & 704 & 1592 & 1816 & 939 & 1145 \\
\hline \multirow[t]{2}{*}{$\operatorname{Max} .2 \theta\left(^{\circ}\right)$} & 50.46 & 49.46 & 50.48 & 50.50 & 50.48 & 50.48 \\
\hline & $-8 \leq \mathrm{h} \leq 9$ & $-9 \leq \mathrm{h} \leq 9$ & $-12 \leq \mathrm{h} \leq 12$ & $-17 \leq \mathrm{h} \leq 17$ & $-10 \leq h \leq 6$ & $-6 \leq h \leq 6$ \\
\hline \multirow[t]{2}{*}{ Ranges (h, k, l) } & $-7 \leq \mathrm{k} \leq 7$ & $-7 \leq \mathrm{k} \leq 7$ & $-8 \leq \mathrm{k} \leq 8$ & $-8 \leq \mathrm{k} \leq 8$ & $-3 \leq \mathrm{k} \leq 5$ & $-12 \leq \mathrm{k} \leq 12$ \\
\hline & $-10 \leq 1 \leq 10$ & $-10 \leq 1 \leq 10$ & $-17 \leq 1 \leq 17$ & $-24 \leq 1 \leq 25$ & $-21 \leq 1 \leq 25$ & $-19 \leq 1 \leq 12$ \\
\hline Completeness $2 \theta(\%)$ & $0.994^{-}-$ & $0.999--2$ & $1.000-$ & $0.996--$ & $0.991--1$ & $0.998--$ \\
\hline Data/restraint/pararmeter & $890 / 0 / 85$ & $894 / 0 / 85$ & $1785 / 0 / 155$ & $1996 / 0 / 182$ & $1673 / 0 / 172$ & $1664 / 0 / 140$ \\
\hline Gof & 1.023 & 1.039 & 1.065 & 1.046 & 1.140 & 0.917 \\
\hline $\mathrm{R}$ indices $[\mathrm{I}>2 \sigma(\mathrm{I})]$ & 0.0380 & 0.0552 & 0.0426 & 0.0870 & 0.0508 & 0.0420 \\
\hline $\mathrm{R}$ indices (all data) & 0.0415 & 0.0708 & 0.0466 & 0.0919 & 0.1027 & 0.0667 \\
\hline
\end{tabular}




\section{Results and Discussion}

\subsection{Structure of salts 1-6}

Salts 1-6 shown in figure 2 are characterized by ${ }^{1} \mathrm{H}-$ NMR, IR, mass spectra and by determining their single crystal structures by X-ray diffraction. Each salt shows ESI-mass for the corresponding cationic part. Chloride salt Hhqn.Cl (1) and bromide salt Hhqn.Br (2) are isostructural. Structure of chloride salt is shown in figure $3 \mathrm{a}$, whereas structure of bromide salt is shown in figure S3. In these two salts, halide-ions are sandwiched between two planar aromatic rings of the cations. Distance between anion and centroid of $\pi$-cloud of cation of the chloride salt $\mathbf{1}$ is $3.374 \AA$; whereas such distance in bromide salt is $3.465 \AA$. These distances are within permissible distances for chloride- $\pi$ interactions..$^{20-27}$ Theses salts form self-assemblies through hydrogen bonds to form layered structure (figure $3 \mathrm{~b}$ ). Pertinent hydrogen bond parameters are listed in table 2. It may be noted that anion- $\pi$ interactions are primarily ionquadrupole interactions and covalent contribution may be absent. DFT calculation has shown that highest occupied molecular orbital (HOMO) shows absence of overlap between chloride and cation (figure S12). Lowest unoccupied molecular orbital (LUMO) shows possibility of an overlap region. Thus, covalent contributions for anion- $\pi$ interactions at ground state had less significance in this salt.

In the crystal lattice of $\mathbf{H h q n . \mathrm { NO } _ { 3 }}(\mathbf{3})$, nitrate ions are hydrogen bonded to four neighbouring $\mathrm{Hhqn}^{+}$ cations (figure 4a). A view along $b$-crystallographic axis shows wave-like layers of ions. Nitrate ions are sandwiched between cations. Two oxygen atoms $\mathrm{O} 4$ and $\mathrm{O} 5$ of a nitrate ion are involved in two bifurcated hydrogen bonds formed by $\mathrm{N} 1-\mathrm{H} \cdots \mathrm{O} 4, \mathrm{~N} 1-\mathrm{H} \cdots \mathrm{O} 5$ and $\mathrm{C} 1-\mathrm{H} \cdots \mathrm{O} 4, \mathrm{~N} 1-\mathrm{H} \cdots \mathrm{O} 4$ interactions. $\mathrm{C} 3-\mathrm{H}$ bonds of cations interact with $\mathrm{O} 5$ atoms of nitrates. There are weak $\mathrm{C}-\mathrm{H} \cdots \mathrm{O}$ interactions between cations. $\mathrm{O} 3$ atom of nitrate anion is hydrogen bonded to an $\mathrm{O}$ $\mathrm{H}$ group of oxime. Crystallographic $a$-direction of the lattice is related by a $2_{1}$-screw axis (figure $4 \mathrm{~b}$ ). Positions of nitrate ions are oblique with respect to cations, they appear in different planes from cations and distance between centroid of anion and cation is 3.099 $\AA$. There exist examples of nitrate ion held within concave aromatic host showing anion- $\pi$ interaction. ${ }^{26}$ There are also examples of nitrate ions possessing $\mathrm{O} \cdots \pi$ interactions with $\pi$-cloud of host. ${ }^{27}$ Nitrate ion placed over naphthalenediimide ring shows weak $\pi$-anion interaction. ${ }^{28,33}$ Pyridine tethered macrocycle shows anion- $\pi$ interaction with nitrate ion. ${ }^{28}$ In salt $\mathbf{3}$ the distance between nitrate and cation is $3.099 \AA$ which is favourable to have anion- $\pi$ interactions. ${ }^{8-12}$ This distance of anion- $\pi$ is shorter than conventional cases, ${ }^{28}$ which is attributed to electrostatic interactions present among the ions playing a primary role in the tight packing. As in the case of chloride salt, DFT calculation shows that symmetry of highest occupied molecular orbital (HOMO) are not suitable for overlap between anion and cations (figure S13).

Perchlorate salt Hhqn.CIO 4 (4) has a layer-like structure and ions interact through hydrogen bonds (figure 5a). Perchlorate ions are held on top of $\pi$-cloud of cations. One oxygen atom of perchlorate ion is disordered. This atom is shown to have equal sharing of electron densities among two equivalent positions (figure $5 b$ ). Distance between oxygen atom and centroid of $\pi$-cloud on cation is $3.253 \AA$, and it suggests a separation conducive for anion- $\pi$ interactions.

To compare orientations of nitrate group in packing patterns of different salts of fused aromatic heterocyclic molecules, structures of nitrate salts of 5aminoquinoline (Hamq. $\mathbf{N O}_{3}, \mathbf{5}$ ), 4-hydroxyquinazoline
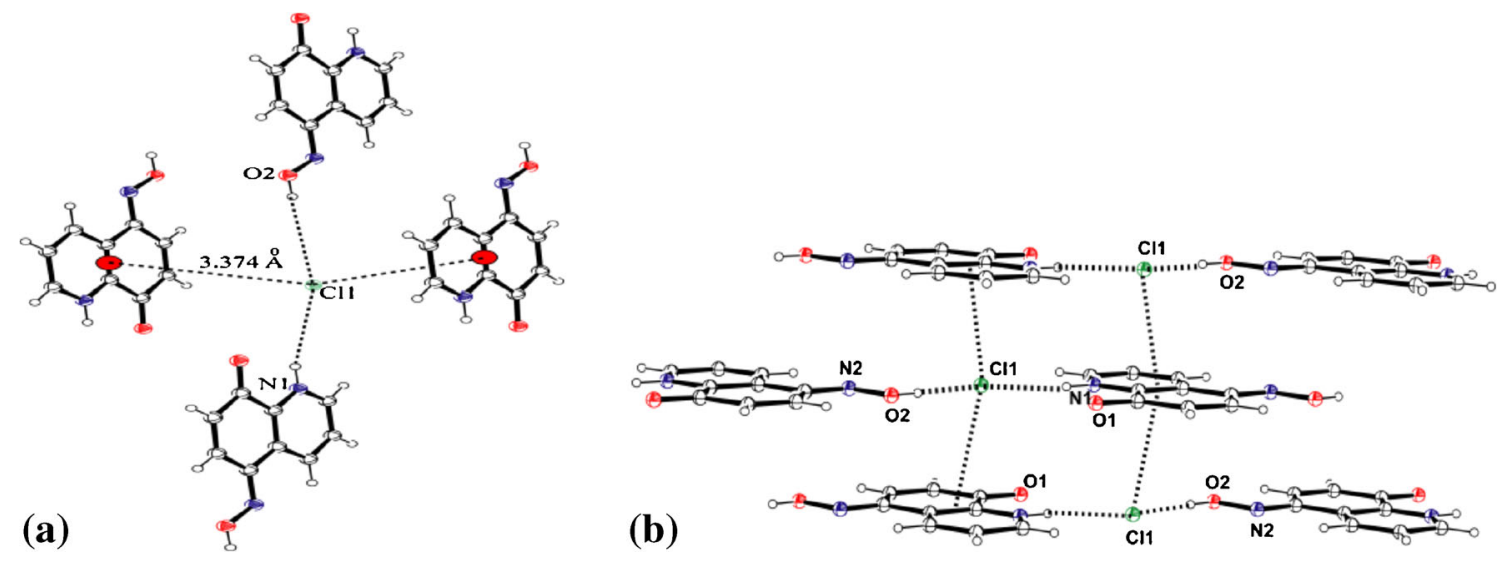

Figure 3. (a) Interactions of chloride with four cations in salt 1; (b) Layered structure of 1 showing hydrogen bonds and anion- $\pi$ interactions. 
Table 2. Hydrogen bond parameters of salt $\mathbf{1}$ and $\mathbf{2}$.

\begin{tabular}{|c|c|c|c|c|}
\hline $\mathrm{D}-\mathrm{H}^{\cdots} \mathrm{A}$ & $d_{\mathrm{D}-\mathrm{H}}(\AA)$ & $d_{\mathrm{H} \cdots \mathrm{A}}(\AA)$ & $d_{\mathrm{D} \cdots \mathrm{A}}(\AA)$ & $\angle \mathrm{D}-\mathrm{H} \cdots \mathrm{A}\left({ }^{\circ}\right)$ \\
\hline \multicolumn{5}{|l|}{ Salt 1} \\
\hline N1-H'Cl1 [1-x,-1/2+y,1-z] & $0.86(3)$ & $2.27(3)$ & $3.078(2)$ & $157(3)$ \\
\hline $\mathrm{O} 2-\mathrm{H}^{\cdots} \mathrm{C} 11[2-\mathrm{x},-1 / 2+\mathrm{y}, 1-\mathrm{z}]$ & $0.82(5)$ & $2.19(2)$ & $3.007(2)$ & $159(2)$ \\
\hline \multicolumn{5}{|l|}{ Salt 2} \\
\hline $\mathrm{N} 1-\mathrm{H}^{*} \mathrm{Br} 1[1-\mathrm{x},-1 / 2+\mathrm{y}, 1-\mathrm{z}]$ & $0.86(3)$ & $2.43(2)$ & $3.242(6)$ & $157(10)$ \\
\hline $\mathrm{O} 2-\mathrm{H} \cdots \mathrm{Br} 1[-\mathrm{x},-1 / 2+\mathrm{y},-\mathrm{z}]$ & $0.82(4)$ & $2.35(3)$ & $3.377(9)$ & $143(7)$ \\
\hline
\end{tabular}

(Hquin.NO $\mathbf{N}_{3}, \mathbf{6}$ ) and 8-hydroxyquinoline (Hhq. $\mathbf{N O}_{3}, 7$ ) are analyzed. For this purpose structure of $\mathbf{5}$ and $\mathbf{6}$ are determined; whereas structure of $\mathrm{Hhq} . \mathrm{NO}_{\mathbf{3}}$ was reported earlier. ${ }^{33}$

In the crystal lattice 5-aminoquinolinium nitrate (5) each nitrate ion surrounded by three 5aminoquinolinium cations as shown in figure 6a. There are several bifurcated hydrogen bonds involved in holding nitrate anion by cations. $\mathrm{C} 1-\mathrm{H}$ bond of a 5aminoquinolinium cation forms bifurcated hydrogen bond with two oxygen atoms of nitro group. There are two other $\mathrm{C}-\mathrm{H}^{\cdots}{ }^{\prime} \mathrm{O}$ interactions namely $\mathrm{C} 8-\mathrm{H}^{\cdots}{ }^{\cdots} \mathrm{O} 3$ and $\mathrm{C} 3-\mathrm{H}^{\cdots} \mathrm{O} 1$ to hold the cations and anions. N1-H bond acts as a pivot for bifurcated hydrogen bonds, $\mathrm{N} 1-\mathrm{H}^{\cdots} \mathrm{O} 2$ and $\mathrm{N} 1-\mathrm{H}^{\cdots} \mathrm{O} 3$ bonds, whereas one of hydrogen atom of $\mathrm{N} 2-\mathrm{H}$ is involved in two hydrogen bonds namely $\mathrm{N} 2-\mathrm{H}^{\cdots} \mathrm{O} 1$ and $\mathrm{N} 2-\mathrm{H}^{\cdots} \mathrm{O} 3$. Hydrogen bond parameters are listed in table 3. Nitrate anions are slightly oblique from plane of aromatic rings of the cations, with $\mathrm{O}$ to $\pi$-centroid distance $3.252 \AA$ in 5 , which shows a possibility to have anion- $\pi$ interactions (figure 6c). 4-Hydroxyquinazolinium nitrate (6), nitrate ions in lattice are surrounded by three 4hydroxyquinazolinium cations. There are two $R_{2}^{2}(7)$ type of hydrogen bond interactions shown in figure $6 \mathrm{~b}$. On the other hand, there is a $\mathrm{C} 3-\mathrm{H}^{\cdots} \mathrm{O} 3$ interaction between the nitrate ion and cation. These interactions generate layer-like structure where nitrate ions occupy places parallel to cations. As a result $\pi$-stacking interactions between cations and anions take place. Distance between parallel pair of cation and anion is $3.322 \AA$ (figure 6d). Stacking interactions present in $\mathbf{6}$ are similar to salt $\mathbf{3}$. The structure of hqn has a layer structure $^{34}$ and we find that salt $\mathbf{5}$ has planar arrangement of anions and cations forming layers which do not show $\pi$-stacking interactions.

\section{$3.2{ }^{1}$ HNMR of salts $\mathbf{1 - 4}$}

These salts exist as ion-pairs in solution, due to which their ${ }^{1} \mathrm{H}-\mathrm{NMR}$ spectra show different chemical shifts for the ring protons. In solution, each salt shows ${ }^{1} \mathrm{H}$ NMR peak due to O-H assigned as $f$ (figure 7) which is assigned on the basis of its presence in the parent compound. This hydrogen peak disappears on deuterium exchange. ${ }^{13} \mathrm{C}-\mathrm{NMR}$ of the nitrate salt shows a peak at $181.4 \mathrm{ppm}$ which is assigned to carbonyl carbon showing the compound remains in keto form. Chemical shift of ring protons differ from case to case and thus suggests a role of anion on chemical shifts. This implies diamagnetic contribution of anion to $\pi$-cloud of cation varies with counter anion suggesting interactions between the counter ions.
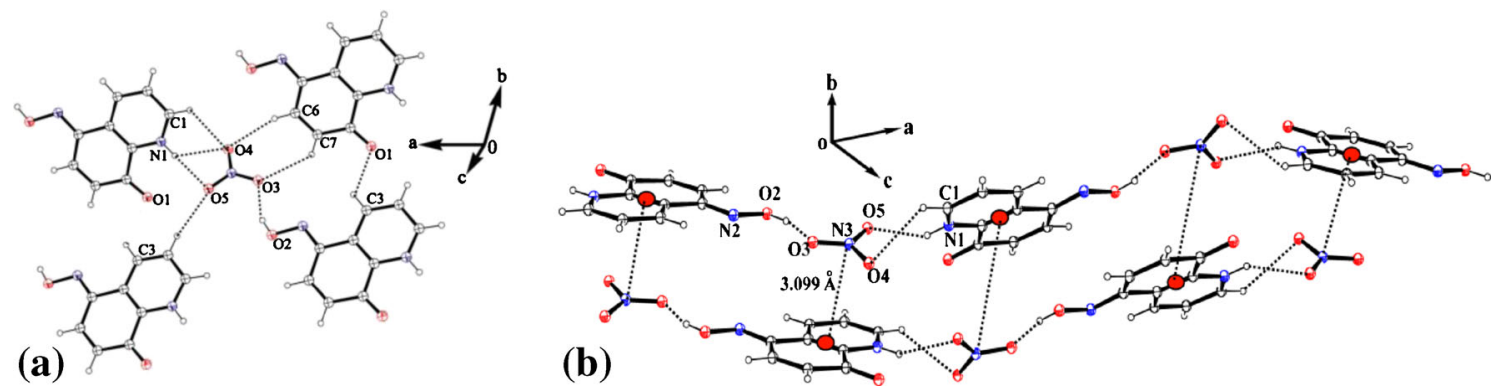

Figure 4. (a) Hydrogen bonds in layered structure of $\mathbf{H h q n} . \mathrm{NO}_{3}$ (3). Some pertinent hydrogen bond parameters are $\mathrm{O} 2-\mathrm{H}^{\cdots} \mathrm{O} 3[1-\mathrm{x}, 1-\mathrm{y}, 1-\mathrm{z}], d_{\mathrm{D} \cdots \mathrm{A}}=2.663(19) \AA, \angle \mathrm{D}-\mathrm{H} \cdots \mathrm{A}=156(3)^{\circ}, \mathrm{N} 1-\mathrm{H}^{\cdots} \mathrm{O} 4[-$ $\mathrm{x},-1 / 2+\mathrm{y}, 1 / 2-\mathrm{z}], d_{\mathrm{D} \cdots \mathrm{A}}=2.966(2) \AA \mathrm{A}, \angle \mathrm{D}-\mathrm{H} \cdots \mathrm{A}=128(2)^{\circ}, \mathrm{N} 1-\mathrm{H}^{\cdots} \mathrm{O}(5)[-\mathrm{x},-1 / 2+\mathrm{y}, 1 / 2-\mathrm{z}], d_{\mathrm{D} \cdots \mathrm{A}}=$ $2.977(2) \AA, \angle \mathrm{D}-\mathrm{H} \cdots \mathrm{A} 154^{\circ}, \mathrm{C} 7-\mathrm{H}^{\cdots} \mathrm{O} 3[1-\mathrm{x},-1 / 2+\mathrm{y}, 1 / 2-\mathrm{z}], d_{\mathrm{D} \cdots \mathrm{A}}=3.229(2) \AA, \angle \mathrm{D}-\mathrm{H} \cdots \mathrm{A}=128(6)^{\circ}, \mathrm{C} 1-$ $\mathrm{H}^{\cdots} \mathrm{O}$ O $[-\mathrm{x},-1 / 2+\mathrm{y}, 1 / 2-\mathrm{z}] 3.087(2) \AA, \angle \mathrm{D}-\mathrm{H} \cdots \mathrm{A}=114(5)^{\circ}, \mathrm{C} 2-\mathrm{H}^{\cdots} \mathrm{O}$ - $[-\mathrm{x}, 1-\mathrm{y}, 1-\mathrm{z}], d_{\mathrm{D} \cdots \mathrm{A}}=3.351(2) \AA, \angle$ $\mathrm{D}-\mathrm{H} \cdots \mathrm{A}=165(2)^{\circ}$. 


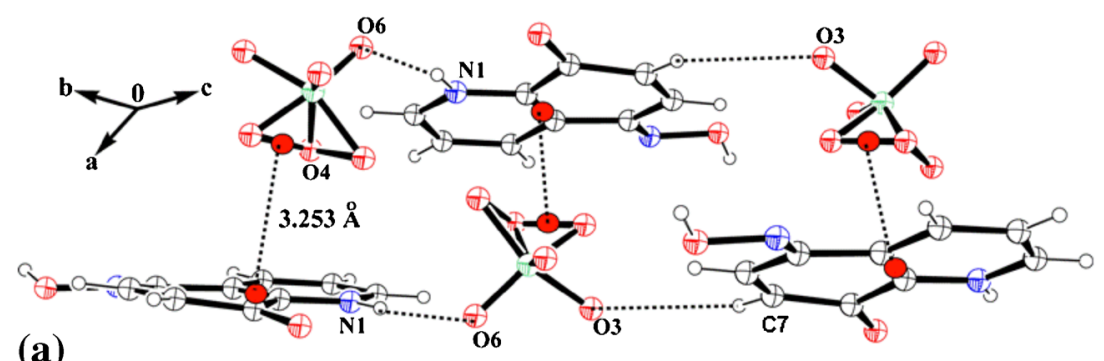

(a)

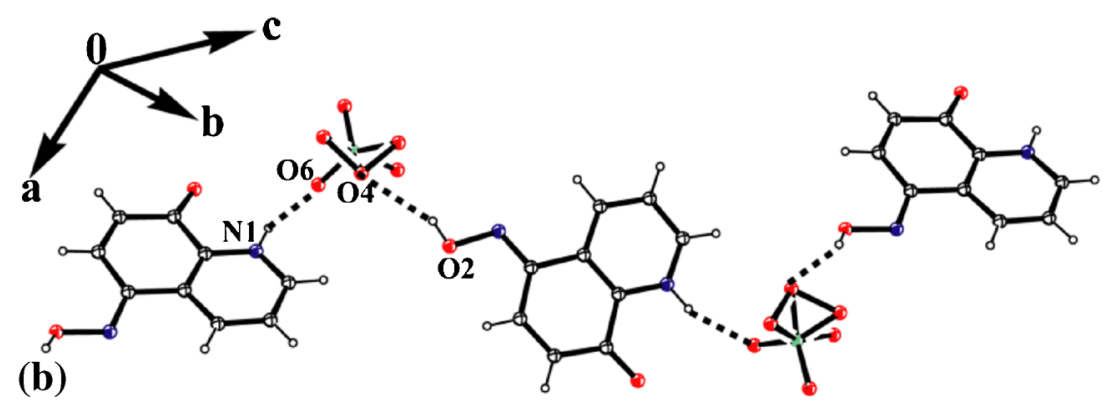

Figure 5. (a) Packing pattern of $\mathrm{Hhqn} \mathrm{ClO}_{4}$ (4). Some relevant hydrogen bond parameters of $\mathbf{4}$ are $\mathrm{N} 1-\mathrm{H}^{\cdots} \mathrm{O}$ O6 [1/2-x, 1/2+y, 1/2-z], $d_{\mathrm{D} \cdots \mathrm{A}}=2.831(12)$ $\AA$; $\angle \mathrm{D}-\mathrm{H} \cdots \mathrm{A}=161(3)^{\circ} ; \mathrm{C} 7-\mathrm{H}^{\cdots} \mathrm{O} 3, d_{\mathrm{D} \cdots \mathrm{A}}=3.361 \AA, \angle \mathrm{D}-\mathrm{H} \cdots \mathrm{A}=128^{\circ}$. $\mathrm{O} 2-\mathrm{H} 2 \cdots \mathrm{O} 4[1 / 2-\mathrm{x}, 1 / 2-\mathrm{y},-\mathrm{z}], d_{\mathrm{D} \cdots \mathrm{A}}=2.836(10) \AA ; \angle \mathrm{D}-\mathrm{H} \cdots \mathrm{A}=129(5)^{\circ}$.

(b) Hydrogen bonds between perchlorate ions with cations.

\subsection{Visible spectra and fluorescence emission of salts}

Compound hqn has a visible absorption at $277 \mathrm{~nm}$ and $432 \mathrm{~nm}$ due to $\pi-\pi *$ and $n-\pi *$ transitions respectively. On protonation of hqn by an acid, intensity of latter absorption decreases. The intensity of peak at $277 \mathrm{~nm}$ increases on addition of nitric acid, similarly addition of nitric acid increases intensity of peaks of 8-hydroxyquinoline 5-aminoquinoline or 4hydroxyquinazoline at $214 \mathrm{~nm}$ (figures S6-S11). From the changes in absorbance by acids, binding constants for salt 3, 5, 6 and $\mathbf{7}$ were determined by using Benesi Hildebrand equation, ${ }^{32}$ which are $2.44 \times 10^{2} \mathrm{M}^{-1}, 4.18$ $\times 10^{3} \mathrm{M}^{-1}, 3.73 \times 10^{3} \mathrm{M}^{-1}$ and $5.42 \times 10^{3} \mathrm{M}^{-1}$ respectively. Magnitudes follow order $7>5>6>>3$. Salts 5-7 have structural similarities, hence differences between their binding constants are nominal. This also suggests that magnitudes of anion- $\pi$ interactions in these salts in solution are small in magnitude. In solid state, salt 7 does not show anion- $\pi$ interactions, yet it shows highest binding constants among three structurally related salts. Binding constant of salt $\mathbf{5}$ is higher

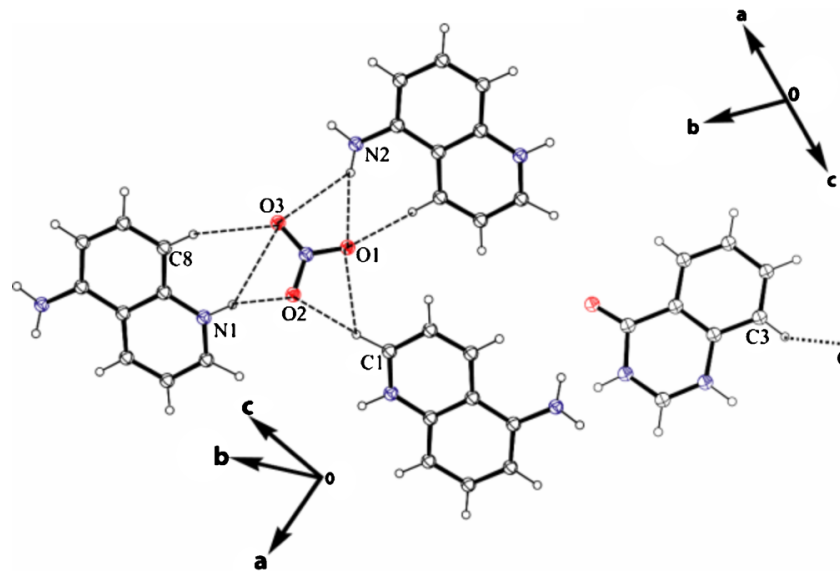

(a)

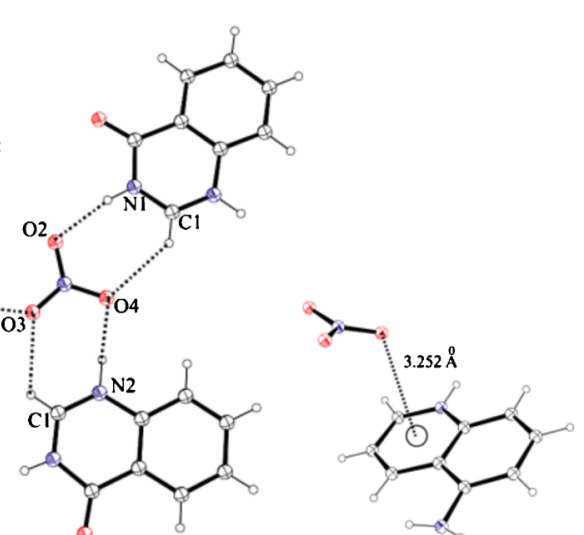

(b) (c)

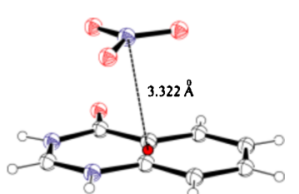

(d)

Figure 6. Hydrogen bonded assemblies of (a) 5-aminoquinolinium nitrate (5) and (b) 4-hydroxyquinazolinium nitrate (6) salts. Anion- $\pi$ interactions in nitrate salts (c) 5 and (d) 6 . 
Table 3. Hydrogen bond parameters of 5-6.

\begin{tabular}{llll}
\hline $\mathrm{D}-\mathrm{H}^{\cdots} \mathrm{A} d_{\mathrm{D}-\mathrm{H}}(\AA)$ & $d_{\mathrm{H} \cdots \mathrm{A}}(\AA)$ & $d_{\mathrm{D} \cdots \mathrm{A}}(\AA)$ & $\angle \mathrm{D}-\mathrm{H} \cdots \mathrm{A}\left({ }^{\circ}\right)$ \\
\hline Salt 5 & & & \\
$\mathrm{N} 1-\mathrm{H}^{\cdots} \mathrm{O} 2[-1+\mathrm{x}, 1+\mathrm{y}, \mathrm{z}]$ & $0.97(3)$ & $1.79(3)$ & $2.726(3)$ \\
$\mathrm{N} 2-\mathrm{H}^{\cdots} \mathrm{O} 1[-1 / 2+\mathrm{x}, 1 / 2+\mathrm{y}, \mathrm{z}]$ & $0.87(3)$ & $2.27(3)$ & $3.129(4)$ \\
$\mathrm{C} 1-\mathrm{H}^{\cdots} \mathrm{O} 1[1-\mathrm{x}, 2-\mathrm{y},-\mathrm{z}]$ & $1.07(3)$ & $2.54(3)$ & $3.249(4)$ \\
$\mathrm{C} 1-\mathrm{H}^{\cdots} \mathrm{O} 2[1-\mathrm{x}, 2-\mathrm{y}, \mathrm{z}]$ & $1.07(3)$ & $2.23(3)$ & $3.287(4)$ \\
$\mathrm{C} 8-\mathrm{H}^{\cdots} \mathrm{O} 3[1+\mathrm{x}, \mathrm{y}, \mathrm{z}]$ & $0.98(4)$ & $2.59(5)$ & $3.394(5)$ \\
$\mathrm{C} 3-\mathrm{H}^{\cdots} \mathrm{O} 1[-1+\mathrm{x}, \mathrm{y}, \mathrm{z}]$ & $0.94(7)$ & $2.47(2)$ & $3.212(5)$ \\
Salt 6 & & & \\
$\mathrm{N} 1-\mathrm{H}^{\cdots} \mathrm{O} 2[-1+\mathrm{x}, \mathrm{y}, \mathrm{z}]$ & $0.86(8)$ & $1.94(6)$ & $2.789(3)$ \\
$\mathrm{N} 2-\mathrm{H}^{\cdots} \mathrm{O} 4[\mathrm{x}, 1 / 2+\mathrm{y}, 1 / 2-\mathrm{z}]$ & $0.96(2)$ & $1.85(2)$ & $2.804(3)$ \\
$\mathrm{C} 1-\mathrm{H}^{\cdots} \mathrm{O} 4[-1+\mathrm{x}, \mathrm{y}, \mathrm{z}]$ & $0.93(4)$ & $2.37(6)$ & $3.115(3)$ \\
$\mathrm{C} 1-\mathrm{H}^{\cdots} \mathrm{O} 3[-\mathrm{x}, 1 / 2+\mathrm{y}, 1 / 2-\mathrm{z}]$ & $0.93(5)$ & $2.38(9)$ & $2.999(3)$ \\
$\mathrm{C} 3-\mathrm{H}^{\cdots} \mathrm{O} 3[-1+\mathrm{x}, 1+\mathrm{y}, \mathrm{z}]$ & $0.93(3)$ & $2.39(5)$ & $3.225(3)$ \\
\hline
\end{tabular}

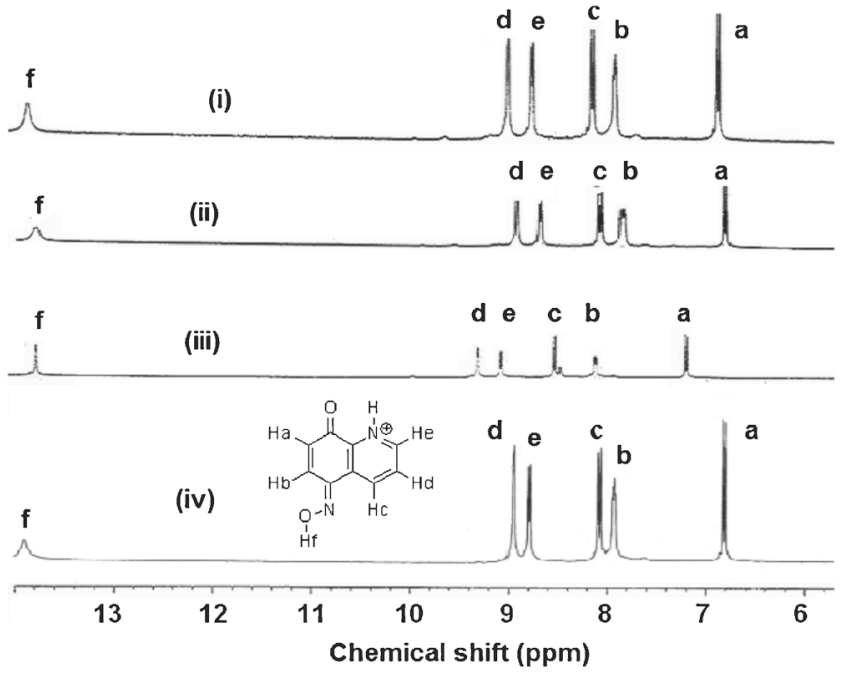

Figure 7. 1H-NMR spectra $\left(400 \mathrm{MHz}, \mathrm{DMSO}^{\left.-\mathrm{d}^{6}\right)}\right.$ of (i) Hhqn.Cl (1), (ii) Hhqn.Br, (iii) Hhqn. $\mathrm{NO}_{3}$, (iv) Hhqn. $\mathrm{ClO}_{4}$ (4) (only peaks in the range of 6-13.8 ppm are shown for clarity).

than salt 6. Hence, anion- $\pi$ interactions could be a cause to make a difference in visible spectra.

Solid sample of hqn as well as salts1-4 shows fluorescence emission different intensities at $504 \mathrm{~nm}$ on excitation at $350 \mathrm{~nm}$. Relative fluorescence emission intensities of salts and parent compound is, nitrate $\approx$ perchlorate $>$ bromide $>5$-(hydroxyimino)quinolin8 -one $>$ chloride. Thus, there is a definite interaction of anion with hqn to cause such changes in emission property.

\section{Conclusions}

It is found that anions are suitably placed to interact with the $\pi$-cloud of cations in layered structures of quinolinium salts 1-7. Sandwiching of nitrate ions between cations in salts $\mathbf{4}$ and $\mathbf{6}$ are observed, whereas nitrates ions occupy oblique with respect to cation in salt 5. These salts remain as strong ion pairs in solution. They have suitable distances to interact through anion- $\pi$ interactions through dispersive forces.

\section{Supplementary Information}

Solid state fluorescence spectra of salts 1-4, spectroscopic titrations for determination of binding constants, table for hydrogen bond parameters of salt $\mathbf{2}$ are given as Supplementary Information. CIF files are available which have CCDC numbers 914799-914801, 914803 and 944121-944122. Supplementary Information is available at ias.ac.in/chemsci.

\section{References}

1. Dawson R E, Hennig A, Wemann D P, Emery D, Ravikumar V, Montenegro J, Takeuchi T, Gabutti S, Mayor M, Mareda J, Schalley C and Matile S 2010 Nature Chem. 2533

2. Jentzch A V, Emery D, Mareda J, Metrangolo P, Resnati $\mathrm{G}$ and Matile S 2011 Angew. Chem. Int. Ed. Eng. 50 11657

3. Guha S, Goodson F S, Corson L J and Saha S $2012 \mathrm{~J}$. Am. Chem. Soc. 13413679

4. Guha S and Saha S 2010 J. Am. Chem. Soc. 13217674

5. Hay B M 2010 Chem. Soc. Rev. 393700

6. Deeshko S, Dechert S and Meyer F 2004 J. Am. Chem. Soc. 1264508

7. Rosokha Y F, Linderman S V, Rosokha S V and Kochi J K 2004 Angew. Chem. Int. Ed. Eng. 434650

8. Quinonero D, Garau C, Rotger C, Frontera A, Ballester P, Costa A and Deya P M 2002 Angew. Chem. Int. Ed. Eng. 413389

9. Quinonero D, Garau C, Frontera A, Ballester P, Costa A and Deya P M 2002 Chem. Phys. Lett. 359486

10. Ahuja R and Samuelson AG 2003 Cryst. Eng. Comm. 5 395 
11. Hay B P and Custelcean R 2009 Cryst. Growth Des. 9 2539

12. Mooibrrek T J, Black C A, Gamez P and Reedijk J 2008 Cryst. Growth Des. 81082

13. Schottel B L, Chifotides H T and Dunbar K D 2008 Chem. Soc. Rev. 3768

14. Davis J T 2010 Nature Chem. 2516

15. Singh A S and Sun S-S 2012 RSC Adv. 29502

16. Bao X-P, Wang L, Wu L and Li Z-Y 2008 Supramolecular Chem. 20467

17. Mateus P, Bernier N and Delgado R 2010 Coord. Chem. Rev. 2541726

18. Bowman-James K 2005 Acc. Chem. Res. 38671

19. Choi K and Hamilton A D $2001 \mathrm{~J}$. Am. Chem. Soc. 123 2456

20. Kang S O, Begum R A and Bowman-James K 2006 Angew. Chem., Int. Ed. Eng. 457882

21. Gale P A 2004 In Encyclopedia of Supramolecular Chemistry J L Atwood and J W Steed (Eds.) (New York: Marcel Dekker)

22. Sessler J L, Cho D-G and Lynch V 2006 J. Am. Chem. Soc. 12816518
23. Schug K A and Lindner W 2005 Chem. Rev. 10567

24. Nath J K and Baruah J B 2013 New J. Chem. 371509

25. Frontera A, Saczewski F, Gdaniec M, DziemidowiczBorys E, Kurland A, Deya PM, Quinonero D and Garau C 2005 Chem. Eur. J. 116560

26. Casellas H, Massera C, Buda F, Gamez P and Reedjik J 2006 New. J. Chem. 301561

27. Wang D-X and Wang M-X 2013 J. Am. Chem. Soc. 135 892

28. Vlaencia L, Bastda R, Gracia-Espana E, de Julian-Ortiz J V, Llinares J M, Macias A and Lourido P P 2010 Cryst. Growth Des. 103418

29. Ishikawa T, Watanabe T, Tanigawa H, Saito T, Kotake K-I and Ohashi H 1996 J. Org. Chem. 612774

30. Isaev A A, Lomovskii II, Korolev K G and Karimov R K 2005 Chem. Heterocyclic Compd. 411027

31. Sheldrick G M 2008 Acta Crystallogr. 64A 112

32. Benesi H A and Hildebrand J H 1949 J. Am. Chem. Soc. 712703

33. Loh W-S, Hemamanlini M and Fun H-K 2010 Acta Crystallogr. 66E o2907

34. Okabe N and Akita M 1997Acta Crystallogr. 53C 1324 